\title{
Investigation and repair of reinforcement corrosion in a bridge deck
}

\author{
P. G. CAVALIER \& P. R. VASSIE
}

\section{Mr Cavalier and Dr Vassie}

Since the Paper was written further testing and repair works have been carried out on bridge decks in Norfolk, and there is a bridge over the River Great Ouse which is thought to represent a typical corrosion situation in a concrete bridge deck which has not been protected by a waterproofing membrane. The $69 \mathrm{~m}$ long three-span bridge was constructed in 1964 with post-tensioned concrete beams supporting a $230 \mathrm{~mm}$ reinforced concrete deck. Initial tests on a small area and visual inspection of the deck after removal of surfacing had not indicated any damage.

65. Data are shown in Table 4. Except at one location a single bar only was corroded, and it is significant that corrosion was found at 19 out of the 20 locations indicated by the half cell tests and that in 15 of these situations the concrete cover was $25 \mathrm{~mm}$ or less.

Mr A. S. Safier, Armand Safier and Partners

I admire the effort that must have gone into the research and the repair work as well as the achievements in that short period between October 1978 and the end of the summer 1979, especially as research into corrosion is normally very long term.

67. As a consulting engineer part of my work since about 1977 has been concerned with research into the nature of reinforcement corrosion, especially in connection with the development and use of electrostatically epoxy-coated reinforcement in the UK. (This can now be obtained in the UK and has recently been used on a bridge here.)

68. The corrosion of reinforcement has, of necessity, received much attention in the USA, and much development has taken place over the last few years. However, from the reference list in the Paper it appears that the Authors have not been able to take advantage of the advances in this field since about 1974 . Of course, there is a wealth of difference between the magnitude of the problem in the UK and the USA. Nevertheless, chemistry and engineering are the same on both sides of the Atlantic.

69. It is evident that chloride ions penetrated into the deck concrete. I wonder if the Authors could give more data on the permeability tests that have been 
published so far. I wonder also whether carbonation has been tested on crack faces (not just on the external faces but on the actual faces of cracks) and if so, what were the results.

70. In $\$ 22$ the Authors say that chlorides penetrating hardened concrete are more corrosive than those added in mixing. This appears to be rather a simplification. CP 110 and other concrete codes do limit chlorides by the total content in the mix and I think that free chlorides are likely to permit galvanic currents to occur, regardless of their origin, other circumstances being equal. Similarly, the assumption of even distribution of chloride levels in $\$ 24$ requires proof.

71. Regarding methods of repair ( $\$ 28$ ), I wonder if the Authors could say how they dealt with locked-in stresses or, in this case, the locked-out stresses in the tensile reinforcement due to dead load.

72. As to the general nature of the corrosion I can do no better than quote from a private communication to me from Mr Kenneth C. Clear, who is in charge of the US Federal Highway Authority's research project on corrosion and who is referred to in the Paper:

'In general, the corrosion evaluation and repair described in the paper was a good one. Several actions were based on my 1974 report. Although not incorrect, we now have a better understanding of the corrosion process. The major points which need to be considered are: iron chloride complexing as the major corrosion reaction with the accompanying large $\mathrm{pH}$ reductions at the anode, and macro-cell action as the primary culprit responsible for high corrosion rates. For example, the black corrosion products mentioned in the paper were undoubtedly lower forms of iron due to the low oxygen concentration. They probably had a $\mathrm{pH}$ of about 5 , while 1 -inch away, the $\mathrm{pH}$ was 11 or 12 . But, we must also remember that the $\mathrm{pH}$ was reduced the steel surface area (and, thus, its ability to reduce oxygen).

Most importantly, we must consider the macroscopic nature of the corrosion process in concrete. This is missed several times in the paper. Note the comments that clean-bar areas were often found adjacent to rusted areas. This is common in that they are cathodic areas and the oxygen reduction there maintains a high $\mathrm{pH}$. Similarly, the comment [\$27] concerning the effects of holidays [i.e., holes] is incorrect. The repair areas are chloride free and, hopefully, will remain so because of the membrane. Thus, they are natural macro-cathodes and will drive corrosion in any surrounding chloride contaminated areas. To minimize their adverse effect (i.e., their ability to reduce oxygen) they must be coated with a non-metallic.

Table 4. Bridge over River Great Ouse

Road surfacing

Cover to reinforcement specified

Chloride content tests

Locations with half cell potentials less than $-0 \cdot 20 \mathrm{~V}$

Locations with pitting corrosion of reinforcement

Locations with surface corrosion of reinforcement
$50 \mathrm{~mm}(\mathrm{~min}$.$) hot-rolled asphalt$

$38 \mathrm{~mm}$

Approx. average $0.8 \% \mathrm{Cl}^{-}$by

weight of cement

20

10 
Holes in the coating would be of little significance since we have greatly reduced the stell surface area (and, thus, its ability to reduce oxygen).

The above effect is slightly different than the effect of holidays on the anode ...

The major problem in the paper, however, is in the discussion in the Appendix on resistance and linear polarization probes. This discussion totally ignores the possibility of macro-cells as the major cause of corrosion. Unless the probes are connected to the rebar [i.e., reinforcement] and become the anode in a macro-cell, they will not viably indicate the high macroscopic corrosion rate existing in the structure; but, rather only the self-corrosion rate of the probe, which we have found to be many orders of magnitude lower than the macro-cell rate in most instances. Installation procedure is critical with probes when tieing them to the rebar since, if they become cathodic to the surrounding rebars, they will never corrode. To prevent this in rehabilitation work when we are leaving chloride contaminated concrete in place, I now commonly place the probe in a small beam of chloride contaminated concrete, excavate completely around the rebar (two adjacent longitudinal and two transverse) in the structure, place the beam between the bars and then patch with chloride-free concrete. When the probe is attached to the rebar lead, a macro-cell is created (probe anode and rebar cathode).

A similar problem exists with the linear polarization technique. It measures only self corrosion. However, there are other potential problem areas with two electrode polarization techniques. IR compensation must be accomplished to prevent measurement errors. Have any weight loss measurements been done (in concrete) to define method accuracy?'

\section{Mr F. Papworth. Taylor Woodrow Construction}

The Authors express three doubts about the effectiveness of the repairs. Therefore, I wonder what consideration they gave to additional protection in each area. Firstly, at the edges, where not only cracking of the sound concrete but also the possible preferential chloride ingress at joints could cause a problem, did they consider coating of the surface or impregnation of the concrete to provide, with the asphalt, a belt and braces solution?

74. Secondly, as they were concerned about the effectiveness of the bond, what are their thoughts on bonding aids? Moreover, did they consider the use of additives in the repair mix to provide a more 'dense, well compacted, low permeability concrete'?

75. Thirdly, protection against differential corrosion cells could be achieved by coating reinforcement in the repair area to provide insulation. I accept the difficulty of coating the under side of bars, but in view of the expense and inconvenience involved in carrying out further repairs after road resurfacing, would this not have been a worthwhile precaution?

\section{Mr G. E. Bratchell, NCL Consulting Engineers}

I have seen local heavy corrosion occurring immediately adjacent to unaffected lengths of re-bar in many cases. It has been suggested that this could be a cell action, but I wondered if it might also be due to salt entry through localized cracks.

77. Is oxygen necessary for the corrosion of steel in these cases, or can the 
metal be completely changed by chloride alone? Is this what produces the black paste deposit? This black paste appears to be ferrous or ferric chloride, and perhaps there is a change in a later stage to the oxides or hydroxides and one gets normal rust. Perhaps the Authors could comment.

78. There is a 1980 amendment to CP 110 , specifically on chloride levels.

\section{Mr M. P. Geoghegan, Tavlor Woodrow Construction}

There is a similar road bridge in Lincoln that Taylor Woodrow Research Laboratories have surveyed. Like the Haddiscoe Bridge much use of deicing salts was made to keep the bridge open during the winter. It has not been possible to have the 'black top' removed from the deck slab but an inspection of the adjacent walkways has been made. On removing the paving stones and sand fill, small localized patches (area $10-100 \mathrm{~cm}^{2}$ ) of red stained concrete surface were discovered. Beneath these, severe localized corrosion of the reinforcing bars was identified very similar to that observed on the Haddiscoe Bridge (Fig. 4). On the Haddiscoe Bridge the Authors have been quite successful at locating these areas of severe corrosion using reinforcement potential measurements taken over a close $(100 \mathrm{~mm})$ grid. However, to cover a large area in the limited time available, Taylor Woodrow used a $1 \mathrm{~m}$ grid; this unfortunately has not been so successful. It appears therefore that this form of localized corrosion may be quite common on bridge decks where deicing salts have contaminated the concrete. Visually the telltale red staining of the concrete surface may be difficult to detect and although potential measurements could be used as a detection method, a large number of measurements must be made using a very close grid.

80. The principal problem investigated on the Lincoln bridge was the reinforcement corrosion initiated by chloride-laden water, leaching through the expansion joints and contaminating the joint soffits and columns beneath. In

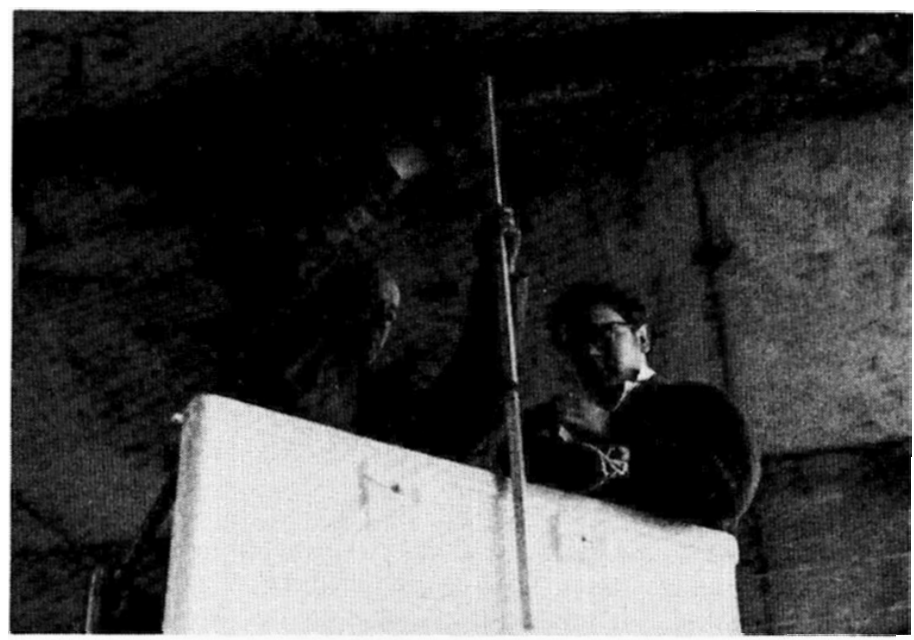

Fig. 13. Taking reinforcement potentials inside an expansion joint gap 
these areas general (and not localized) reinforcement corrosion was identified which had in places caused cracking and spalling of the cover. By taking reinforcement potentials over a fairly wide grid (approx. $1 \mathrm{~m}$ ), which was easily accomplished even for soffits (Fig. 13), a better definition of the areas requiring remedials could be obtained than purely by visual survey. The potential readings were recorded on a pro forma sheet of the member and iso-potential contours were drawn using the -200 and $-350 \mathrm{mV} v$. copper/copper sulphate electrode Van Daveer criteria. ${ }^{12}$ A typical example is given in Fig. 14. From these sheets the local authority were able to make decisions on which areas of concrete required remedial treatment. The repairs to this structure are discussed by Evans and Lee. ${ }^{13}$

81. From the survey of this and other structures inspected by the Taylor Woodrow Research Laboratories, a point of interest arose concerning the ingress mechanism of chloride into concrete. In many locations, the chloride concentration profile with depth could be explained assuming that ingress was by a simple diffusion mechanism. ${ }^{14}$ Theoretical diffusion profiles are given in Fig. 15 and by fitting the chloride ingress data to them (determined from drillings) both a diffusion coefficient and surface level could be estimated. The Authors say that they discarded the top $6 \mathrm{~mm}$ of concrete when analysing for chloride. This assessment of both diffusion coefficient and surface level were very sensitive to the amount of chloride in this concrete and Taylor Woodrow would certainly have analysed it.

82. Van Daveer ${ }^{12}$ observed (in bridge decks) that when the chloride level at reinforcement depth exceeds about 0.4 wt $\%$ (of cement) activation of rebar

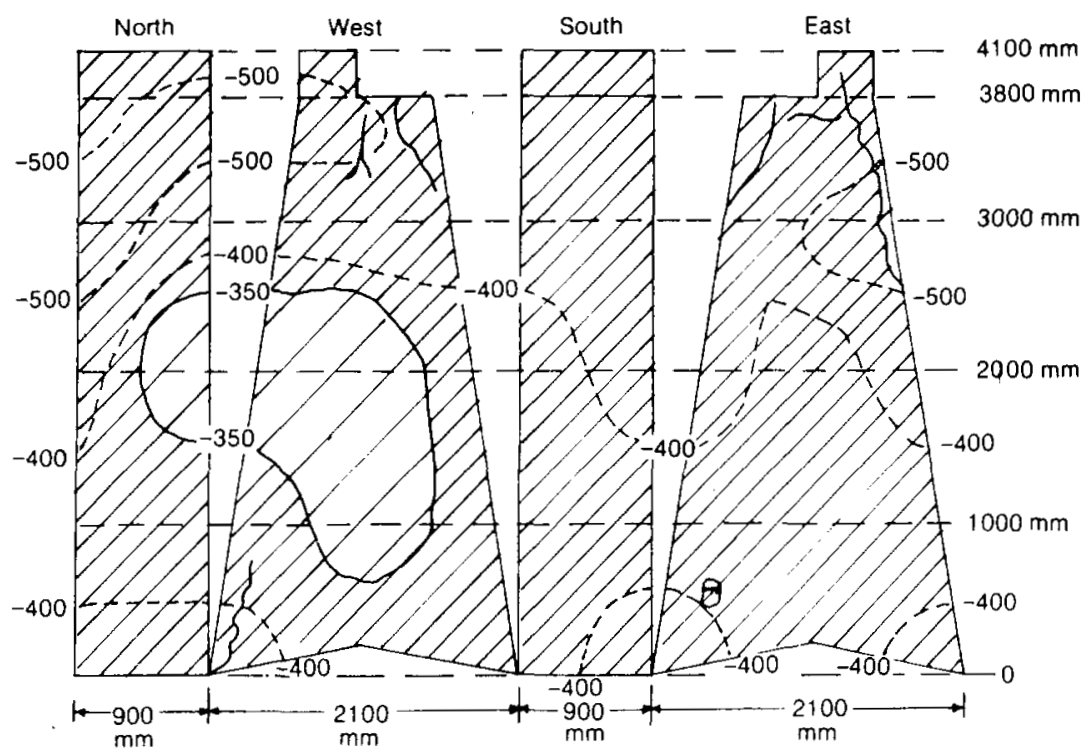

Fig. 14. Iso-potential contours in millivolts $v$. copper/copper sulphate electrode on a column of the Lincoln bridge 


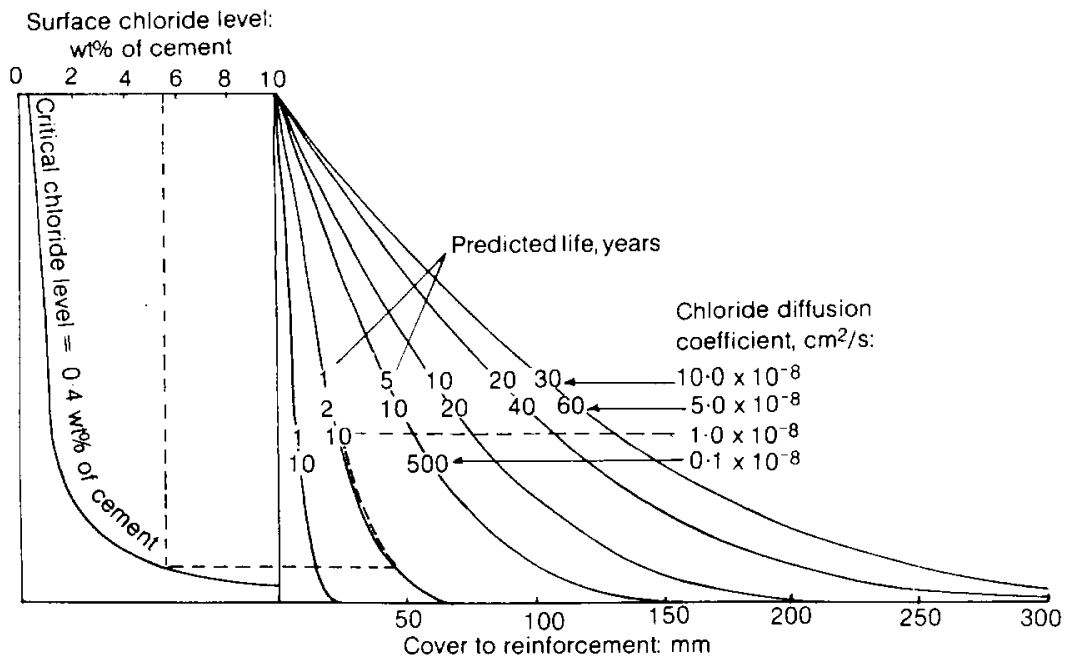

Fig. 15. Prediction of time to activation of reinforcement corrosion where chloride enters by diffusion

corrosion occurred. Fig. 15 is a simplified diagram of a graphical method used by Taylor Woodrow either to predict the time required for ingressing chloride to activate reinforcement or to estimate the period for which the reinforcement has been active. The figure shows that for a chloride surface level of $5 \frac{1}{2} \%$ and a diffusion coefficient of $1 \times 10^{-8} \mathrm{~cm}^{2} / \mathrm{s}$ it would take about 10 years for enough chlorides to reach the reinforcement at $50 \mathrm{~mm}$ cover to activate corrosion. With these assessments Taylor Woodrow have been able to make useful predictions of the potential durability of structures exposed to chloride environments.

Mr K. M. Brook, Wimpey Laboratories Ltd

I agree that the absence of the waterproofing membrane is one of the main factors for the trouble which has occurred on this bridge, but in addition I was interested $(\$ 41)$ in the presence of shrinkage cracks in the concrete which arose by virtue of the way in which the bridge was constructed-the timber beams being left in as a support for the screeding operations, and subsequently removed, and fresh concrete being used for filling in. The inference is that the shrinkage cracks between the two concretes have allowed chlorides to penetrate down to the reinforcement. This seems to be backed up by the indications in some of the slides of a line along which the corrosion had occurred. I wonder if the Authors could comment on this.

84. Figure 4(a) shows in the top of the slab quite a congested arrangement of reinforcement-longitudinal and transverse bars. Excavating the concrete to a depth of $75 \mathrm{~mm}$ (including removing the concrete from under the bars) must have been quite a difficult task to have carried out with pneumatic breakers without causing damage to the bars and without a great deal of difficulty in breaking out. Could the Authors say something about the practical difficulties which were encountered in what seemingly was a basic simple breaking-out operation? 
85. I was interested in the distinction between the chloride which is the free ion and the chloride which is bound up with other compounds in the concrete. I have only been aware of chloride contents in concrete as total values. I wonder if the Authors would say how the two values were determined.

Mr A. R. Murray, Sir Alexander Gibb and Partners

It is likely to be increasingly the case that bridges which were constructed some 20 years ago without waterproofing may need repair.

87. In the light of their experience in the $2 \frac{1}{2}$ years since they did work, would the Authors do anything different in retrospect?

88. Where the concrete was cut out to a depth of $25 \mathrm{~mm}$, I wonder if there has been any problem as that seems rather a thin layer to replace.

89. Concerning the half cell potential measurements, it is intimated that only a single electrical connection to the reinforcement is necessary. It would be helpful if the practical arrangements of this could be explained.

90. I would be interested if the Authors would comment on the suggestion that epoxy or some other such additive would have been advantageous in the replacement concrete.

\section{Mr Safier}

It is right in the chemical sense that oxygen is necessary in a very small amount to permit corrosion to proceed but not in the way normally understood, because that small amount of oxygen can arise from within the concrete, being created by electrogalvanic processes or out of the saline solution. This is the reason why the initial product of pitting corrosion is a lower form of iron which then oxidizes once exposed to the air for a couple of days, and where it can obtain oxygen freely.

92. The Authors seem to think $(\$ 27)$ that electrostatic-epoxy-coated reinforcement would not be helpful in providing insulation. It is true that on rare occasions holes can occur in the electrostatic coating, but it is the large mass of the reinforcement which allows the corrosion process to take place and the few holes do not really matter. In the USA hundreds of thousands of tons of electrostatic coated reinforcement have by now been used. The coating is not painted on; this type of coating is not subject to rust creep that occurs with a layer of paint or a metallic layer on steel. There are special factories and standards for it. Where there is ice or where there is a marine environment, no state in the USA will now receive Federal funds for highway construction unless it uses epoxycoated reinforcement.

93. The Americans have carried out accelerated ageing tests, on sites and in laboratories, on a large number of large slab samples; many of these were instrumented, and the tests were at various chloride levels. I have seen examples where holes were deliberately induced in the epoxy coating. The first laboratory samples were cast horizontally. The concrete on top of the reinforcement is quite different from that underneath, as one obtains different permeabilities depending on the obstruction to compaction caused by the reinforcing bar. It was found that where holes were deliberately induced and the concrete placed in saline solutions the corrosion only occurred locally at the holes and only on the lower side of the reinforcement where the most permeable concrete was; there was no progression of the corrosion and it did not undercut the epoxy coating. 
94. The bridges constructed in the USA since about 1973 have been troublefree without membranes. There is no reason at all, once the system is stable, for corrosion to commence later. The design in the USA is for a 50 year period, as opposed to the 100 or 200 year notional design life of UK bridges. The Americans feel that if no corrosion occurred in the first 50 years, nothing will happen in 120 years either. They think it is not reasonable to guarantee structures for 120 years and I fully support that opinion.

95. Basically the Authors do not express $100 \%$ confidence in the repair described in the Paper. Anything that could improve that confidence and make it more likely that the repair will be all right surely should be advantageous. I cannot see how, if one had used coated reinforcement, it would have detracted from such confidence. The Americans work on that principle and have been very successful with it. The Authors think that the repair is going to be all right, but none of us, because it is new work, can guarantee that, and the more one does the better.

\section{Mr M. B. Leeming, Construction Industry Research and Information} Association

One gets the impression from the discussion that all that is necessary for corrosion of steel reinforcement is the presence of water and chlorides. In its programme of research on concrete in the oceans, CIRIA has had reinforced concrete samples with quite wide cracks at $150 \mathrm{~m}$ depth in sea water for nearly four years now with abundant supplies of these two materials with little sign of corrosion. The corrosion problem is much more complex. To measure only chloride levels in order to detect corrosion is oversimplifying the problem. So too is the taking of potential readings alone, particularly when the readings indicate that the potential is neither definitely active nor definitely passive. We at CIRIA have dealt with reinforced concrete with chloride contents well above the critical level and potentials in the active corrosion region yet little corrosion has occurred because there are many other factors in the corrosion equation, and the availability of oxygen is certainly one of them. Resistivity of concrete is another link in the corrosion cell. In its research on concrete in the oceans, CIRIA is looking into this factor and that of oxygen diffusion through concrete and trying to find their effect on the corrosion rate of reinforcement.

97. As regards electrostatic coatings on bars, I am concerned about pinholes and other small defects in the coatings. To illustrate one of the dangers of local corrosion small concrete samples, cracked to the reinforcement (uncoated) and immersed in sea water, have been artificially maintained at an active corrosion potential and even after 18 months showed no external sign of corrosion. On breaking them open $40 \%$ of the diameter of the bar was found to be rusted away. Considerable local corrosion can occur which reduces the structural integrity of the reinforcement. However, general corrosion soon produces spalling of the concrete surface with little loss of steel cross-section, giving an outside indication of what is going on under the surface. On seeing this one can take remedial action.

98. Another factor being looked at in the concrete in the oceans programme is the influence of crack width on the amount of corrosion of steel reinforcement in concrete exposed to sea water. No evidence has so far been found that crack widths that would normally occur in good concrete (i.e., widths resulting from good design practice) have any significant influence on corrosion rates. As a 
result much wider cracks are now being looked at. In this context it would be interesting to know how wide the crack was at the centre-line of the bridge.

99. Significant corrosion, however, has been found on reinforcement with cracks running along the bar, as there is a considerable area of steel exposed at the root of the crack.

\section{Mr Bratchell}

The question of oxygen penetration is very important to the profession because there is a school of thought which says that if there is onset of corrosion this can be retarded by entirely coating the outside of the reinforced concrete member. If that is a false view the sooner we find out the better.

\section{A speaker}

I know that in the USA there is considerable interest in minimizing the water/ cement ratio and the resultant permeability of any repair concrete. What are the Authors views on water/cement ratio, permeability and resultant shrinkage potential in the standard repair concrete that they used? Was it a simple mix or were there additives?

Mr K. P. Mackie, Fisheries Development Corporation of South Africa Ltd $I$ have previously had the problem of a cost overrun on a contract for the repair of a jetty deck where the billed quantities were estimated by visual inspection of the deck surface. On opening up, the extent of the corrosion to the reinforcement was found to be much greater than anticipated.

103. The method described by the Authors seemed to be a very useful, practical method for monitoring the condition of jetty decks and of surveying the extent of repairs which might be required. I therefore arranged to test the method on two jetties in Hout Bay.

104. Both jetties were designed to BS CP 114 and 2007. Cover was generally $60 \mathrm{~mm}$ to main steel but crossfall increased this to about $100 \mathrm{~mm}$ on the centre-line of the jetties.

105. The one jetty was built in 1974 and is protected from splash and spray. On opening up, the reinforcement was found to be in 'as fixed' condition with the millscale still intact. Nineteen copper sulphate half cell readings were taken on the concrete up to $2.6 \mathrm{~m}$ from the exposed reinforcement. The readings were in the range of $-145 \mathrm{mV}$ to $-175 \mathrm{mV}$. There was no sign of surface cracking in the deck and I was satisfied that the reinforcement in the deck of this jetty is not corroding.

106. The other jetty was built in 1968 and is exposed to considerable splash and spray. It also has a fair amount of cracking in the deck and a fair amount of rust staining. The deck was opened up at a long crack at the site of a rust stain. The region around the reinforcement was found to be damp, and pitting corrosion had reduced the cross-section of the rod by about $20 \%$. Five half cell readings to a distance of $2.5 \mathrm{~m}$ along the crack ranged from $-385 \mathrm{mV}$ to $-500 \mathrm{mV}$. Corrosion appeared to be severing the reinforcement along the line of the crack. Within $300 \mathrm{~mm}$ of the crack the readings were $-365 \mathrm{mV}$ to one side and $-425 \mathrm{mV}$ on the other side. Away from the crack to a distance of $2.6 \mathrm{~m}$ six readings ranging from $-142 \mathrm{mV}$ to $-195 \mathrm{mV}$ were obtained on one side and three readings from $-185 \mathrm{mV}$ to $-325 \mathrm{mV}$ were obtained on the other side. It would seem that 
serious corrosion is taking place in the deck of this jetty but that it is generally restricted to the regions of cracks.

107. Samples of powdered concrete from drill holes were taken for chloride analysis but reliable results are not yet available.

108. It would appear that systematic surveys by copper sulphate half cell alone are quite sufficient for most applications.

109. The climate at Hout Bay is relatively mild compared with the conditions at sites on the dry west coast. At these sites all the jetty decks exhibit plastic shrinkage cracking caused by the free water evaporating from the surface while the concrete is setting. I have not been able to establish how significant this form of cracking is - the crack in the older jetty at Hout Bay was a structural crack-but it would certainly seem advisable to investigate methods of sealing the surface immediately the concrete has hardened.

110. For the remainder of jetty structures, I have noticed that corrosion does in fact concentrate in the splash zone and in particular it starts at the edges of rectangular beams and columns. The soffits of flat slabs in this zone seem to be relatively free of corrosion. I can only suggest that concrete jetties be constructed of flat slabs and round columns.

\section{Dr D. G. Manning and Mr P. Smith. Ministry of Transportation and Communications, Ontario}

The Paper brings into focus the difficulty of identifying deterioration in concrete deck slabs with a bituminous surfacing. This is one of the most serious problems facing highway authorities. Reliable information on the condition of the deck slab is needed for the purposes of inventory, capital programming and execution of repairs.

112. The type of deterioration observed at the Haddiscoe Bridge was typical of that found in North America in bridge decks which had a bituminous surfacing, but no waterproofing membrane, before the use of air-entrained concrete became widespread. ${ }^{15}$

113. The description of the damage does not follow the normal pattern of corrosion-induced distress but appears to be the result of severe scaling of the concrete, which exposed the bars to corrosion. If the concrete is sound, a pit depth of as little as $0.03 \mathrm{~mm}$ has been found sufficient to crack a $22 \mathrm{~mm}$ thick concrete cover. ${ }^{16}$ Deep pitting of the steel, with significant loss of crosssection, occurs only when corrosion continues and the steel is no longer confined by the concrete, such as in an open spall or in porous or scaled concrete. ${ }^{17}$

114. At Haddiscoe, the worst scaling occurred in the three central spans, and particularly in the kerb areas, where the drainage was poor. Even high strength concrete will deteriorate when exposed to freezing and thawing in a saturated condition in the absence of an adequate air void system. The deterioration is aggravated by the presence of de-icing chemicals. The substantial loss of section and deterioration of the concrete shown in Fig. 4 indicates that some parts of the bridge deck had been deeply scaled and the corrosion had occurred over a long period of time before the macadam surfacing was removed.

115. The relationship between concrete resistivity and corrosion activity reported in Table 2 is valuable because it provides a method of assessing the vulnerability to corrosion damage of reinforced concrete which either contains chlorides or is exposed to chlorides in service. It will be helpful if the Authors reference the source of Table 2 . 
116. In work carried out in Ontario, but not yet published, it has been found that corrosion activity is very sensitive to changes in resistivity within the range of approximately $5000-8000 \mathrm{ohm} \mathrm{cm}$. These results confirm that for concrete which is intermittently wetted and contains chloride in excess of the threshold value, corrosion is almost certain when the resistivity is less than $5000 \mathrm{ohm} \mathrm{cm}$. However half cell potentials were found to be in the passive range for resistivity values greater than about $8000 \mathrm{ohm} \mathrm{cm}$.

117. The discussion of the acceptable level of chloride in concrete is very topical. As noted by the Authors, the threshold value is presently considered in North America to be $0.15 \%$ soluble chloride ion by mass of cement. The value is based on the work of Clear ${ }^{8}$ and Lewis ${ }^{9}$ and has been confirmed by field studies on bridge decks, including those in California ${ }^{18}$ and New York. ${ }^{19}$ It is stated $(\$ 25)$ that the Lewis and Clear figures are accepted as conservative. Is this the view of the Authors or the consensus of technical opinion in the UK? In view of the difference between the acceptable levels of chloride in North America and CP 110, and the fact that German and other European practice is different again, will the Authors describe the basis for the figures used in CP 110 ?

118. A definition of the term 'free chloride' used in Table 3 is needed. It is also necessary to define whether the term 'chloride added to the mix' is only that which is intentionally added to the concrete mixture or also includes that which is naturally present in all the mix ingredients. If the Authors are using the term 'free chloride' to be the proportion of the chloride which is intentionally added to the mix and which is water-soluble in the hardened concrete, then the figure of 0.2 appears low. A ratio of water-soluble chloride to total added chloride as high as 0.87 has been reported. ${ }^{20}$ These difficulties highlight one of the most pressing research needs, which is a test method to measure only the chloride in concrete which is available to initiate corrosion of embedded steel.

119. There is danger of misinterpreting the statement, "Thus chlorides penetrating hardened concrete are more corrosive than chlorides added to the mix' (\$22). A more precise statement would be: 'A greater proportion of chlorides from external sources than chlorides added to the mix ingredients are available to initiate corrosion. The non-uniform penetration of external chlorides promotes the development of concentration cells.'

120. As noted by the Authors, establishing a level of chloride content as a criterion for concrete removal is difficult. However, in rationalizing the decision made at Haddiscoe and reported in $\S 25$, there is a danger of confusing theoretical and economic considerations. In North America the removal of all the concrete containing chloride in excess of threshold values for corrosion is not a consideration on many bridge decks because the concrete is physically sound and the cost of removal would exceed the cost of deck replacement. Consequently many decks are repaired by removing unsound concrete but not all that which is chloride-contaminated. Although it is known that corrosion will continue, such repairs can still be cost-effective. However, generalizations are dangerous because there are wide variations in age and condition of the bridges under the jurisdiction of a single authority. It is for this reason that Ontario now uses a systematic approach to surveying the condition of bridge decks, selecting the most appropriate method of repair and preparation of the contract documents. Three methods of repair are now used: patch, waterproof and pave (as at Haddiscoe), concrete overlay and cathodic protection. Details of the selection criteria and construction methods are given elsewhere. ${ }^{17,21}$ 


\section{Mr Cavalier and Dr Vassie}

Mr Safier refers to advances since about 1974. Excluding British Standards, five out of nine references given in the Paper were dated after 1974, and these were not intended to constitute a comprehensive list. We were aware of at least some of the recent American work, an excellent summary of which is given in NCHRP synthesis $57 .{ }^{17}$

122. The American problem is not the same as the UK one since in the USA the concrete is used as running surface, and waterproofing membranes are generally not used. Both these factors influence the chemistry and engineering of the system.

123. Permeability measurements were not made at Haddiscoe. There is no adequate technique for determining concrete permeability in situ. Permeability measurements can be made on cores by measuring water flow rates under hydrostatic pressure. Because of the concrete variability a large number of cores would have to be taken in order to get a representative value for permeability and its variance.

124. Carbonation tests were not carried out on crack faces. Although carbonation generally penetrates more rapidly down cracks, if the crack is fine the $\mathrm{pH}$ can subsequently increase due to diffusion of $\mathrm{OH}^{-}$ions from the uncarbonated concrete adjacent to the crack. The only cracks at Haddiscoe were fine.

125. Chlorides penetrating hardened concrete are more corrosive because they result in a higher free $\mathrm{Cl}^{-}$ion concentration than the equivalent amount of $\mathrm{Cl}^{-}$added to the mix. Free chloride ion is the only form of chloride which produces corrosion.

126. We agree that the assumption in $\$ 24$ requires proof. It does seem clear, however, that if further ingress of chlorides is prevented, then the chloride level at any point in the deck should not exceed the level in the surface layer at the time of repair, especially since diffusion processes would tend to equilibrate the $\mathrm{Cl}^{-}$concentration.

127. The repair has locked dead load stresses into the deck, but as the self weight moment of the concrete deck was only $3 \%$ of the deck resistance moment, the additional stresses are small. The deck will only be overloaded by the heaviest abnormal vehicles, which can be routed elsewhere.

128. As stated in the Paper ( $\$ 45$ ) corrosion of deck reinforcement was of the pitting type, severe pitting being found adjacent to uncorroded reinforcement. It has been established that during pitting corrosion the $\mathrm{pH}$ of the solution in the pit becomes substantially reduced. The mechanism for high corrosion rates at pits results from the fact that the reinforcement which is in electrical contact with the pitting steel and is within a reasonable distance from the pit, acts as a cathode. When a large cathode is connected to a small anode the rate of corrosion at the anode can be very high, because the total anode current is equal to the total cathode current during a corrosion process; it follows that the anode current density can be high. The domain of influence of a given anode will be largely dependent on the concrete resistivity in that region (the cathode area is usually limited by the concrete resistivity since in a bridge deck all of the steel could be in electrical contact and this could, in theory, act as a cathode to one anode region). Another way of looking at pitting corrosion is that rapid metal dissolution at the anode is effectively protecting the surrounding steelwork from corrosion to which it may otherwise be subject. This view is supported by the fact that at a number of places in the cathode region the chloride level was 
significantly in excess of the generally accepted threshold level for corrosion. It could be that pits are formed at points where the chloride level first exceeds the threshold value (e.g., areas of low cover); when at a later time the chloride concentration at other points exceeds the threshold level pitting is prevented here by the protective action provided by rapid corrosion occurring at the first-formed pit. (In America, this type of localized corrosion is called macro-cell corrosion, but this terminology is not often used in the UK.) It is a natural consequence of the localized corrosion described that it was caused by small anode/large cathode or macro-cell mechanism. Hence, we would not agree that the macroscopic nature of corrosion has been missed several times in the Paper. It was not the purpose of this Paper to discuss the theory of corrosion in any detail. Macro-corrosion cells and $\mathrm{pH}$ reduction in pits are discussed elsewhere by Vassie. $^{11}$

129. We would agree that the black deposit found in the pits when initially exposed was a lower oxide of iron, since if left open to the atmosphere for a few days this was converted to the fully oxidized red-brown ferric oxide, common rust. Also, as the corrosion deposit migrated to the concrete surface to form a visible rust deposit, its colour changed from black to red-brown, since on its leaving the pit the oxygen level increases, thus allowing oxidation to occur. It is only the contents of the pit which have reduced oxygen concentration; the oxygen content of the bulk concrete is usually sufficient to ensure full oxidation.

130. We are not clear why Mr Safier (in his second contribution) says that oxygen is not necessary for corrosion 'in the way normally understood'. We see no possibility under anything approaching normal conditions for oxygen to be produced within the concrete by 'electrogalvanic processes'. The solubility of oxygen in saline solution is very low and would only be sufficient to sustain extremely low corrosion rates, as indicated by the results from specimens submerged in sea water during the Concrete in the Oceans programme (i.e., oxygen levels in submerged concrete are insufficient to produce significant corrosion even though the chloride concentration may be high, as stated in Mr Leeming's contribution). Hence in our view oxygen in the normally understood way is required for corrosion to proceed. Concrete exposed to the atmosphere is not usually in a fully saturated condition and hence contains some pores which are air-filled, and the oxygen from these air-filled pores is usually sufficient to sustain a significant rate of corrosion provided that the other necessary conditions for corrosion are satisfied.

131. In general, when applying a protective coating to steel it is important to completely clean the steel surface before coating. In practice this may not be possible on bars in situ. Discussion contributors suggest that uncoated bars in a repair patch can provide a large cathode area which will drive corrosion in adjacent chloride-contaminated concrete. At Haddiscoe, the work involved not only the repair of corroded areas, but also the removal of chloride-contaminated concrete from non-corroding areas. Hence it is unlikely that sufficient potential difference would be generated between the repaired reinforcement and the original reinforcement to produce new corrosion. In fact, potential measurements on the repaired and adjacent areas indicated that corrosion was not taking place in the period between completion of concrete repairs and the laying of the waterproofing membrane.

132. The American practice is usually to repair only corroding areas although this is regarded as only a temporary measure since at the moment no 
satisfactory, established method is available to repair corroding reinforcement in a chloride contaminated deck without removing concrete containing chloride concentrations in excess of the threshold value. A powder epoxy coating on the repaired area reinforcement will prevent that steel from acting as a cathode, but this is hardly significant unless most of the reinforcement in the deck is epoxycoated, since otherwise there will be no shortage of the original reinforcement available to act as a cathode.

133. Mr Safier does not indicate how the bars in the repair patch would be epoxy-coated. If the original reinforcement is cleaned and the epoxy coating applied, this cannot be done by the electrostatic process used in factory production. It would, we think, be necessary to use a liquid epoxy coating, which is known to be inferior to the electrostatically applied power coating. Also, because of difficulties in obtaining effective bar cleaning there is the possibility that chloride-contaminated rust will be left in intimate contact with the steel and that the coating will not bond adequately. If, however, all the reinforcement in the repair patch is to be cut out and replaced with new powder-epoxy-coated bars, various practical difficulties will be encountered. For example, it will not be possible to replace all the reinforcement in the repair patch since substantial lengths of the original reinforcement must remain to be lapped with the new reinforcement. In structures with significant dead load stresses in the reinforcement, it would not be possible to cut out all the bars in a repair and replace with epoxy-coated bars. At Haddiscoe use of epoxy coating could not have increased our confidence because the greater part of the old reinforcement would have had to remain to provide bond lengths, the repaired areas being mainly in strips at right angles to the main reinforcement.

134. If one wanted to insulate the reinforcement in the repair patch so that it could not act as a cathode, a better way might be to use an epoxy mortar repair material with high resistivity instead of cement mortar. This procedure ensures that all the bars in the repair patch are insulated. However, unless most of the deck is repaired, the reduction in the cathodic area obtained by using epoxy-coated bars or epoxy mortar fill would not be sufficient to prevent the formation of new pits in the chloride-contaminated original concrete. There is one technique which can in principle draw the chlorides out of the concrete non-destructively, but this has not proved practically feasible. ${ }^{22}$ At Haddiscoe the heavily $\mathrm{Cl}^{-}$contaminated concrete was physically removed and replaced with fresh concrete. While this is an expensive and slow operation and sometimes complete deck replacement would be as cheap, the only effective way of making long-lasting repairs is to remove the chloride from the concrete to below the threshold level; it remains the best form of long term repair that is currently open to us.

135. We do not wish to suggest that epoxy-coated reinforcement does not have its uses; for new construction or complete deck reconstruction its application looks very promising. We do not understand the claim that epoxy-coated reinforcement is used in patch repairs on US bridge decks, since in discussion with Mr Clear a colleague recently ascertained that epoxy-coated bars are not normally used in this type of repair, but that they are regularly used in new construction or deck reconstruction. ${ }^{23}$ We also believe that the Federal Highway ruling concerning the provision of funds applies to new construction/reconstruction and not to repairs (cf. NCHRP synthesis $57^{17}$ ).

136. We agree that resistance and linear polarization probes as used only 
measure the general corrosion rate and we do indicate that these methods have their limitations when one is trying to measure localized corrosion rates. There is as yet no satisfactory method of measuring localized reinforcement corrosion rates. Our probes were located in the repaired concrete; in such positions anodic sites are unlikely to form and hence it is only meaningful to measure general corrosion rates. It was, of course, not possible to place probes in the original concrete adjacent to a repaired patch without completely altering the conditions.

137. Mr Clear's method of estimating localized corrosion rates by setting the probe in a block of chloride-contaminated concrete within the repair patch and electrically connecting the probe to the reinforcement network is ingenious, but has some drawbacks. For example, the corrosion rate measured will be dependent on the physical and chemical properties of the concrete block in which the probe is placed (e.g., chloride ion concentration, hydroxyl ion concentration, permeability, resistivity etc.). Unless these are similar to the properties of the original concrete surrounding the repair the measured corrosion rate will not be representative.

138. We agree that $I R$ potential drop compensation is a problem with the linear polarization method and hence (as indicated in the Paper) it can only be used in concrete having a reasonably low resistivity. Weight loss methods for determining reinforcement corrosion rates have proved to be practically very difficult, especially if the corrosion is localized.

139. Mr Papworth and Mr Safier refer to areas which gave concern or less than $100 \%$ confidence. A basic assumption was that the waterproofing membrane would prevent any future ingress of water at joints or cracks. Tests by a specialist had shown that impregnation of the concrete with polymers could not be carried out. Special bonding techniques at the joint and elsewhere were considered, but it was decided to use the method described which is based on recommendations for the repair of concrete roads. ${ }^{24}$ For the large amount of repair work envisaged, there were considerable economic advantages in the use of a cementicious bonding technique combined with high strength, qualitycontrolled, site-batched concrete, with properties similar to those of the existing concrete.

140. Several contributors ask about concrete mixes; we can only suggest using the lowest water/cement ratio consistent with obtaining good compaction in the site circumstances; air entrainment or other additives might well be used to advantage. On smaller repair works, where quality control of concrete might not be practical, we would prefer to use special concretes or mortars. The use of epoxy mixes may also be preferable in positions where a waterproofing membrane is not applied, such as for a coping or a bridge substructure. We do not see their advantage for a large repair with a membrane covering-where ordinary concrete of good quality provides an alkaline environment for the protection of the reinforcement - unless their insulating properties are required.

141. The philosophy to be applied in repair work is a difficult subject and to have $100 \%$ confidence may not be compatible with cost-effectiveness, which is discussed by Dr Manning and Mr Smith. Mr Safier says that in the USA, bridges without waterproofing membranes have been stable since 1973 . We prefer the approach in the UK where membranes have been considered the first line of defence and were made mandatory in 1965 .

142. In answer to Mr Bratchell, salt entry through localized cracks is one of the ways in which a corrosion cell may be set up since it would lead to higher 
concentrations of chloride at one place on the bar than at adjacent points. Oxygen is needed for corrosion since the cathodic reaction $\left(\mathrm{O}_{2}+2 \mathrm{H}_{2} \mathrm{O}+4 \mathrm{e}=\right.$ $4 \mathrm{OH}^{-}$) consumes oxygen. If there is no oxygen at the cathode corrosion will cease.

143. We would agree with Mr Bratchell that the provision of an oxygenimpervious coating over the entire concrete surface would probably reduce the corrosion rate, but we are doubtful of the feasibility of completely coating all the concrete surface, and gaps may result in the formation of differential oxygen concentration cells. We also understand that the coatings available have a limited life. $^{25}$ (The question of the colour of the corrosion product is discussed in $\$ 129$.)

144. We agree with Mr Geoghegan that in order to detect all the anodic sites it is necessary to use a close grid, normally $150 \mathrm{~mm}$, for potential measurements where corrosion is localized. This does involve a large number of measurements and TRRL are currently investigating methods of automating the datacollection procedure.

145. At Haddiscoe we discarded the top $6 \mathrm{~mm}$ of chloride drillings as we felt that the concentration of $\mathrm{Cl}^{-}$in the surface layer might be unnaturally high. ${ }^{2}$ As a result it would not be possible to fit the chloride depth data obtained at Haddiscoe to one of the standard diffusion curves. However, fitting chloride analysis data to diffusion curves is a promising method of fixing the time when corrosion commences and hence finding the time before corrosion starts and the time interval of active corrosion. In this way one could predict the future performance of reinforcement.

146. There are some difficulties with this approach, however. The passage of chlorides through concrete is not necessarily by a simple diffusion mechanism (e.g., bulk migration can also occur); and the curve-fitting process is very sensitive to the surface layer chloride concentration as this is one of the boundary conditions in Ficks diffusion equation and is, itself, susceptible to distortion due to contamination. Another problem is the choice of threshold chloride concentration. Taylor Woodrow use $0.4 \% \mathrm{Cl}^{-}$by weight of cement, but different values have been used by other workers (Clear, Lewis, CP 110), and it is not clear which is correct. In practice the threshold chloride level is probably not the fixed quantity it is usually taken to be, but varies with a wide range of other concrete properties (e.g., cement content, permeability, oxygen content, resistivity, and hydroxyl ion concentration).

147. Mr Brook asks about the corrosion along the length of the centre-line of the bridge, and this is also referred to by Mr Bratchell and Mr Leeming. It was felt essential to record that, whereas most of the corrosion had a random distribution over the deck, the centre-line corrosion had a distinct pattern. The construction method was the obvious explanation for the nearly continuous line of corrosion, but no specific measurements were made at the small shrinkage crack visible in places. It is not known to what degree the crack or the poorer quality of the infill concrete was responsible for the penetration of the contaminated water which caused the corrosion; it would not have been suspected from visual examination of the deck, but for the patches of stained concrete.

148. Mr Brook refers to the practical difficulties and the congested reinforcement, which is due to the lapping of the main reinforcement at the centre-line, making breaking out more difficult at this situation. Elsewhere there was no congestion, and after some experience, selected labour was able to break out the concrete with minimal damage to the reinforcement, though it was hard to control 
vertical overbreak below $75 \mathrm{~mm}$ depth. The vertical groove cut to $25 \mathrm{~mm}$ at every edge was essential. It was stipulated that if main bars were damaged, additional reinforcement would be necessary, involving extra breaking out to provide bond lengths, and this encouraged careful workmanship.

149. It is only free chloride ions which can cause reinforcement corrosion; combined chloride in cement hydration products does not directly influence the corrosion process. It is correct that chloride measurements are normally presented as total chloride but as it is the free chloride ions which are most significant in these circumstances, it is important to look for methods that can give this information. TRRL measured free chloride ion concentration by extracting the $\mathrm{Cl}^{-}$from the powdered concrete sample, with a range of volumes of distilled water for a fixed time. The chloride concentration calculated from chloride analysis of the extracts was plotted against volume of water used, and the linear plot obtained was extrapolated to a water volume approximately equivalent to concrete moisture content. We would not claim that this method is very accurate, but it did give values of free chloride ion concentration/total chloride ion concentration similar to those found by other workers. A better method has recently been developed at Aston University, where the liquid phase of the concrete is squeezed out under high pressure, but this requires special equipment.

150. Mr Murray refers to the concrete which was cut out to $25 \mathrm{~mm}$ depth only. This part of the work was specified for two reasons: first, there was concern that migration of chlorides from the top $25 \mathrm{~mm}$ might subsequently increase the concentration at the reinforcement and cause corrosion, and secondly, the work would be of an investigatory nature and should reveal any local corrosion. In view of the successful use of half cell tests to find local corrosion and reduced concern on the first point, the amount of this work was later reduced. The replacement of this layer was closely supervised and the bonding was proved where a $25 \mathrm{~mm}$ groove was cut through the ends of the repair without causing debonding. In future we would prefer not to carry out this part of the repair work.

151. In the light of our experience we would also choose a rather different approach to the testing for chloride content. Having established a likely depth profile for chloride content, we would determine the chloride content at the top level of the reinforcement, by collecting from drillings, say $10 \mathrm{~mm}$ above to $10 \mathrm{~mm}$ below this level. We would also have to consider carefully any research and development on mechanisms controlling the mass transfer of chloride ions in concrete.

152. As to the electrical connections for half cell testing, it has been shown that over large areas the reinforcement in a bridge deck is in electrical continuity. It is only necessary to break out and connect to one bar of the top reinforcement, for each length of deck having electrical continuity.

153. We agree with Mr Leeming that corrosion of concrete reinforcement is influenced by several of the physical and chemical properties of the concrete, not simply the chloride level. The most important chemical properties are probably the chloride ion concentration, hydroxyl ion concentration, and oxygen concentration of the concrete, and the most important physical properties are the permeability and resistivity of the concrete. Many of these factors are interrelated and influenced by the exposure conditions, thus further complicating the situation. A knowledge of oxygen diffusion rate through concrete would certainly provide useful information about corrosion rate when the oxygen-reduction reaction at the cathode is the rate-limiting step in the corrosion process. However, it is 
important to remember that sometimes the corrosion rate is controlled by $\mathrm{Cl}^{-}$ diffusion rate or the concrete resistivity.

154. We are pleased to note that Mr Leeming supports our observations that whereas small amounts of general corrosion cause spalling or cracking of the concrete which can be easily seen, localized corrosion can progress with substantial loss in bar cross-section without any visual indication at the concrete/air interface. This emphasizes the importance of non-destructive half cell potential measurements to locate areas of localized corrosion.

155. We were pleased to hear of Mr Mackie's success with half cell potential measurements, but would not agree that these measurements alone are sufficient for most applications. The half cell potential method only locates areas of corroding reinforcement; it does not give any information on the causes of corrosion or its rate. All this information is required in order to make a satisfactory repair specification.

156. We thank Dr Manning and Mr Smith for their valuable contribution.

157. Although small amounts of general corrosion can produce spalling or cracking we have certainly found some deep pits which have not produced cracking or spalling and which were not associated with scaled or porous concrete. It was not possible to detect these pits by visual observations of the concrete surface, which again highlights the importance of the half cell method for locating anodic sites. However, some of the pitted reinforcement at Haddiscoe was associated with severely frost-damaged (scaled) concrete.

158. The resistivity measurements in Table 2 are based on TRRL investigations using test beams and reinforced concrete structures; further work is being carried out on this topic. The critical resistivity values Dr Manning and $\mathrm{Mr}$ Smith have obtained in Ontario are similar to ours and those obtained by Taylor Woodrow Research Laboratories. ${ }^{26}$

159. We think it would be reasonable to say that it was the consensus view in the UK that the Lewis and Clear value for threshold chloride level is regarded as somewhat conservative. In the UK the slightly higher figure of $0.4-1.0 \%$ total $\mathrm{Cl}^{-}$ by weight of cement is used, ${ }^{27}$ but to properly compare the values it is necessary to make some estimate of the proportion of the chloride content which is in the form of free $\mathrm{Cl}^{-}$ions.

160. We do not know the basis for the CP 110 figures, but it is evidently unsatisfactory that accepted threshold chloride levels vary so much. This may reflect the fact that chloride concentration is not the only factor causing corrosion (the threshold level will vary depending on other properties of the concrete).

161. We apologize that our explanation of the term 'free chloride' was confusing. To clarify the position, we mean by 'chloride added to the mix' all the chloride present in the mix, and by 'free chloride' all chloride which is watersoluble in hardened concrete regardless of its origin. We have not obtained free/total chloride ratios as high as $\mathbf{0 . 8 7}$; most of our results were in the range $0 \cdot 5-0.6$.

162. We fully agree with $\operatorname{Dr}$ Manning and Mr Smith's clarification of our comments on the corrosivity of chlorides from different sources.

163. We agree that there is a danger of confusing theoretical and economic situations when establishing a criterion for concrete removal. The remarks on procedures in North America are very relevant and it is noted that in many repairs, while unsound concrete is removed, concrete which is physically sound but which is chloride-contaminated is left in place. This type of repair will have 
a limited life and if a waterproofing membrane is then applied, the difficulties of detecting and repairing future corrosion will be considerable. We agree that the condition of the bridge deck should be surveyed and the most appropriate method of repair chosen, complete replacement being one of the options to be considered.

\section{References}

12. Van Daveer J. R. Techniques for evaluating reinforced concrete bridge decks. J. $A m$. Concr. Inst., 1975, Dec., 697-704.

13. Evans R. A. and Lee D. M. B. Corrosion fight on Pelham Bridge, Lincoln. Highw. Engr, 1981, Oct., 16-21.

14. BRowne R. D. The mechanisms of corrosion of steel in concrete in relation to design, inspection and repair of offshore and coastal structures. Performance of concrete in the marine environment: proceedings of conference held in St Andrews, New Brunswick, Canada, 1980. American Concrete Institute, SP 65.

15. Armstrong M. D. and WaWrzynski J. The condition of concrete bridge decks in Ontario. Proc. 44th convention Canadian Good Roads Assoc., 1963, 142-154.

16. Spellman D. L. and Stratfull R. F. Chlorides and bridge deck deterioration. Highw. Res. Rec., 1970, No. 328, 38-49.

17. Durability of concrete bridge decks. Transportation Research Board, Washington, 1979, NCHRP synthesis 57.

18. Stratfull R. F. et al. Corrosion testing of bridge decks. Trans. Res. Record, 1975, No. 539, 50-59.

19. Chamberlin W. P. et al. Waterproofing membranes for bridge deck rehabilitation. Federal Highway Administration, 1977, report FHWA-NY-77-59-1.

20. Manning D. G. and Chojnacki B. Concrete overlays for the protection of reinforced concrete against corrosion. Durability of building materials and components. American Society for Testing and Materials, 1980, ASTM STP-691, 193-205.

21. Manning D. G. and Ryell J. Decision criteria for the rehabilitation of concrete bridge decks. Trans. Res. Record, 1980, No. 762, 1-9.

22. LANKARD D. R. Neutralisation of chloride in concrete. Federal Highway Administration, Washington, 1975, report FHWA-RD-76-60.

23. BishOP R. R. (Transport and Road Research Laboratory). Private communication, 1981.

24. Walker M. J. Techniques for the repair and maintenance of concrete roads. Munic. Engng, 1968, 9 Aug. (Cement and Concrete Association reprint 113.)

25. Shaw J. D. N. Discussion: Concrete deterioration and repair. Proc. Instn Civ. Engrs, Part 1, 1981, 70, May, 330.

26. Browne R. D. Marine durability survey of the Tongue Sands Tower. Cement and Concrete Association, Wexham Springs, 1980, Concrete in the Oceans technical report 5 .

27. EveretT L. H. and Treadaway K. W. J. Deterioration due to corrosion in reinforced concrete. Building Research Establishment, Garston, 1980, IP 12/80.

\section{Corrigenda}

Reference 3: for 'MANning D. G. and Ryde J.' read 'Manning D. G. and Ryell J.' Reference 6: for correct form see reference 12. 